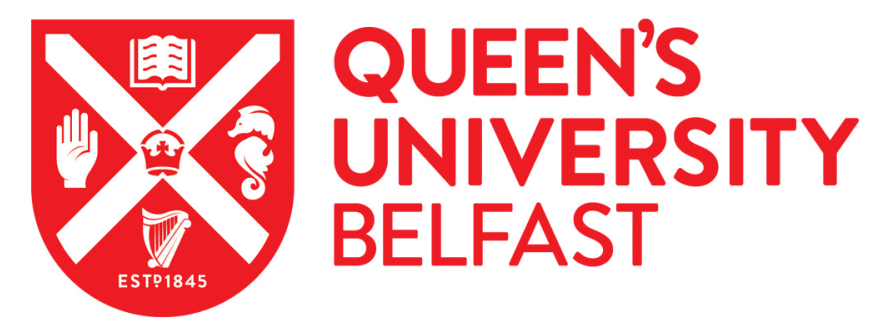

\title{
Qualitative Comparative Analysis as a Tool for Concept Clarification, Typology Building, and Contextualized Comparisons in Gender and
} Feminist Research

Ciccia, R. (2016). Qualitative Comparative Analysis as a Tool for Concept Clarification, Typology Building, and Contextualized Comparisons in Gender and Feminist Research. Politics \& Gender, 12(3), [e8].

https://doi.org/10.1017/S1743923X16000374

Published in:

Politics \& Gender

Document Version:

Peer reviewed version

Queen's University Belfast - Research Portal:

Link to publication record in Queen's University Belfast Research Portal

Publisher rights

This article has been published in a revised form in Politics \& Gender, http://dx.doi.org/10.1017/S1743923X16000374. This version is free to view and download for private research and study only. Not for re-distribution, re-sale or use in derivative works. COPYRIGHT: @ The Women and Politics Research Section of the American Political Science Association 2016

\section{General rights}

Copyright for the publications made accessible via the Queen's University Belfast Research Portal is retained by the author(s) and / or other copyright owners and it is a condition of accessing these publications that users recognise and abide by the legal requirements associated with these rights.

\section{Take down policy}

The Research Portal is Queen's institutional repository that provides access to Queen's research output. Every effort has been made to ensure that content in the Research Portal does not infringe any person's rights, or applicable UK laws. If you discover content in the Research Portal that you believe breaches copyright or violates any law, please contact openaccess@qub.ac.uk. 


\section{Qualitative comparative analysis as a tool for concept clarification, typology building and contextualized comparisons in gender and feminist research}

\section{Introduction}

Qualitative Comparative Analysis (QCA) is a method for the systematic analysis of cases. A holistic view of cases and an approach to causality emphasizing complexity are some of its core features. Over the last decades, QCA has found application in many fields of the social sciences. In spite of this, its use in feminist research has been slower, and only recently QCA has been applied to topics related to social care, the political representation of women, and reproductive politics. Feminist researchers still privilege qualitative methods, in particular case studies, and are often sceptical of quantitative techniques (Spierings 2012). These studies show that the meaning and measurement of many gender concepts differ across countries and that the factors leading to feminist success and failure are context-specific. However, this scholarship struggles to systematically account for the ways in which these forces operate in different locations.

The aim of this article is to demonstrate that QCA and related techniques contribute to enhance comparative analysis in ways which aligns with core ideas in gender and feminist studies. I begin by describing the main principles of QCA as a research strategy. The following sections draw on recent contributions in comparative social policy and politics literature to illustrate how it is used to deal with issues of concept clarification and measurement, policy complexity, the presence of hybrids and the development of normative types and context-sensitive causal analysis. Finally, this article concludes by discussing promising avenues for future applications of QCA in feminist research.

\section{Principles of QCA}

QCA is a research strategy that aims to combine in-depth knowledge of cases with the goal of generalization (Ragin 1987). The key features of this approach are different from (but not necessarily opposite to) those of statistical analysis. First, QCA conceives cases as holistic entities that cannot be decomposed into single variables/properties. Secondly, QCA envisions causal processes in terms of set-relations or relations of implication between phenomena. It starts from maximum complexity of conditions and outcomes, and uses Boolean truth tables to identify sub-sets of conditions that engender particular outcomes. It follows that: (a) conditions often display their effect only in combinations with others (conjunctural causation); (b) a given condition may well have different effects depending on the context (contextual effects); (c) alternative sets of conditions may produce the same outcome (equifinality); (d) the conditions for the occurrence and non-occurrence of an outcome are generally different (asymmetrical causation) (Schneider \& Wagemann 2012). 
This vision of causality well-reflects feminist understanding of socio-political phenomena as inherently complex, local, and historically contingent (Spierings 2012).

Since QCA was first introduced in the social sciences (Ragin 1987), the initial framework has been extended to include different techniques. While QCA originally operated only on dichotomous sets where cases could either be a member (1) or non-member (0) (csQCA), recent developments allow for any degree of membership between 0 and 1 (fsQCA). For instance, a country with a fuzzy score of 0.8 on the set of gender equality is more gender equal than gender unequal, but still falls short from fully realizing gender equality. Closely related to QCA is the use of fuzzy-set-ideal-type-analysis (hereafter FSITA) to develop typologies. This approach is common in comparative welfare state literature where typologies have played an important role in the development of the field.

\section{Fuzzy sets as a tool for concept clarification and typology building}

FSITA takes a deductive approach to typologies. It starts from a concept of theoretical interest, translates it into sets, that then combine into a number of configurations (or ideal types), and uses fuzzy set principles to compute memberships in those configurations. This method has been used in cross-national analysis of childcare policies. An and Peng (2015) and Szelewa and Polakowski (2008) refer to the concept of defamilialization in their typology, while Ciccia and Verloo (2012) and Ciccia and Bleijenbergh (2014) use Fraser's (1994) models of gender division of labour. Both concepts have long standing traditions in the gender and citizenship literature, but their success has also generated conceptual confusion. Empirical analyses use different labels to identify similar models leading to poor systematization of existing knowledge, while defamilialization has been reworked by 'mainstream' research in such a way as to dilute its gendered meaning. Given FSITA emphasis on theory-driven measurement, these studies have helped to draw out crucial dimensions that more closely reflect feminist debates about gender inequalities in the division of labour. For instance, indices of generosity are commonly used in cross-national analyses of leave policies. These measures conflate time and money provisions that are known to have very different effects on gender equality -long leaves are detrimental for maternal employment regardless of levels of payment. FSITA can incorporate this criticism because it relies on set intersections, if a country offers low payments, it cannot compensate for this by offering long durations (Ciccia \& Verloo 2012). Another misunderstanding concerns the relationship between generosity and gender equality, which are often considered different aspects of leave policies. Ciccia and Verloo (2012) rely on set intersections to clarify that generosity is as a necessary precondition of gender equality since equally few rights for men and women do not promote gender equality. FSITA enhances our ability to theorize about the meaning of multiple dimensions, also those that are apparently contradictory. 
Secondly, FSITA has been used in feminist welfare state research to deal with hybrid cases showing characteristics of more than one model. Their existence is well-recognized in feminist literature. Borchorst and Siim (2008) observe, for instance, that Fraser's models coexist in Scandinavian countries and are the object of contention between various societal and political actors. This insight is not reflected in research practices that aim at reducing cases to few unambiguous types. Fuzzy scores allow instead greater transparency and insight on the co-existence of multiple gender models. Since ideal types are based on analytical distinctions, they need not to be mutually exclusive and may coexist because of the complexity of the social world. This is reflected in the use of partial memberships to allocate cases to configurations.

Finally, FSITA is also used to develop normative typologies. The search for policies to diminish gender inequalities is an underlying motive of feminist scholarship. In empirical analyses, this often entails the selection of benchmark cases to evaluate other countries' performance. For instance, Nordic countries are generally portrayed as the most genderinclusive model of citizenship in spite of persisting gender inequalities in many areas (e.g. unpaid work, occupational segregation, glass ceilings and the incorporation of minority ethnic and migrant women) (Borchorst \& Siim 2008). This insight is lost with inductive methods (e.g. relative indices, cluster analysis) which define gender equality based on the cases included in the analysis. FSITA instead can accommodate more utopian ideas because ideal types are theoretical constructs with no empirical validity. Indeed, no country represents Fraser's universal caregiver model (Ciccia \& Bleijenbergh 2014), but this is still used to measure cross-national differences and identify particular aspects of improvement, as well as to inform policy and normative debates.

\section{Qualitative comparative analysis as a tool for contextualized causal explanation}

Studies using QCA within an explanatory framework are more easily found in the gender and politics literature. Krook (2010) and Lilifeldt (2012) use csQCA to investigate factors explaining differences in levels of descriptive political representation of women. These studies aim to move beyond deterministic explanation and incorporate suggestions from previous research about the influence of specific combinations of factors. Krook aims to assess the influence of combinations of institutional, cultural and socio-economic variables, while Lillifeldt seeks to account for the interaction of intra- and extra-party factors. QCA offered some substantial advantages in dealing with these questions. The exploratory nature of Lilifeldt's study required a technique that allowed for openness towards the empirical combinations of conditions leading to high/low female representation. Although she could have used interactions, she was constrained by the low number of cases considered. Moreover, higher order interactions are difficult to interpret in regression analysis, while they 
are more easily treated with QCA. Therefore, she used conjunctures to highlight causal complexity and identify diverse and context-specific pathways towards similar outcomes ${ }^{1}$.

Krook (2010) further exploits this feature of QCA to adjudicate between the contrasting findings of large-N statistical analysis and cases studies. Her intuition is that many of these contradictions derive from the diversity of factors at work in different contexts. Therefore, she draws attention to the importance of avoiding one-size-fits-all kind of reasoning. By comparing Western and sub-Saharan countries using context-specific measures of conditions and outcomes, Krook is able to identify different causal mechanisms leading to similar outcomes in the two regions. Her 'unorthodox' approach explains patterns in the data that had been previously noticed but not adequately theorized. The goal of her study is to offer a more accurate account of developments within each group of countries. Indeed, QCA produces 'modest' generalization which are valid only for the specific contexts from which the original findings are drawn, or ones which are closely similar. Yet, this feature can be used to extend the geographical focus of comparative analysis by reassessing the validity of theories, concepts and indicators developed for the Western world to other regions.

Finally, several authors suggest that QCA could advance the empirical study of intersectionality. Hancock (2013) points to fsQCA as a technique amenable to incorporate both systematic commonalities (categorical intersections) and variation (diversity within) among groups in a way that is sensitive to the historical context and the dynamic interaction within individuals, groups and institutions. Although McCall (2005) does not refer explicitly to QCA, her intercategorical approach with its focus on multi-group relations and the study of multiple configurations of inequality hints in that direction. In spite of the affinity between QCA and key principles of this theory, there is no study to date applying this method to intersectionality $^{2}$

\section{Conclusions}

Qualitative comparative analysis is an important addition to statistical techniques and case studies for comparative gender studies. By formalizing case-oriented analysis, it enhances our understanding of issues related to the complexity of cases and the diversity of causal mechanisms at work in different settings. In spite of its strengths, QCA is no magic bullet. Being based on set-theoretical thinking, it is best suited to answer a particular set of questions related to associations of implications between socio-political phenomena, while it is ill equipped for detecting correlations. In this view, QCA and regression analysis could be best applied next to one another

QCA has been successfully applied in gender analysis of macro phenomena, small or medium-N studies and cross-sectional analysis. Few studies have instead tried to incorporate time (An \& Peng 2015; Szelewa \& Polakowski 2008), or to explain the influence of sociopolitical actors on policy change (Engeli 2012), and none has used large-N or individual-level 
data in spite of increase developments in this area. Particularly remarkable is the lack of studies using QCA to advance comparative research on intersectionality. All these areas point at interesting directions for further QCA applications in gender and feminist research.

\section{References}

An, Mi Young, and Ito Peng. 2015. "Diverging Paths? A Comparative Look at Childcare Policies in Japan, South Korea and Taiwan." Social Policy \& Administration Article first published online: 7 APR 2015 DOI: 10.1111/spol.12128.

Borchorst, Anette, and Birte Siim. 2008. "Woman-Friendly Policies and State Feminism Theorizing Scandinavian Gender Equality." Feminist Theory 9(2): 207-24.

Ciccia, Rossella, and Inge Bleijenbergh. 2014. "After the Male Breadwinner Model? Childcare Services and the Division of Labor in European Countries." Social Politics: International Studies in Gender, State \& Society 21(1): 50-79.

Ciccia, Rossella, and Mieke Verloo. 2012. "Parental Leave Regulations and the Persistence of the Male Breadwinner Model: Using Fuzzy-Set Ideal Type Analysis to Assess Gender Equality in an Enlarged Europe." Journal of European Social Policy 22(5): 507-28.

Da Roit, Barbara, and Bernhard Weicht. 2013. "Migrant Care Work and Care, Migration and Employment Regimes: A Fuzzy-Set Analysis." Journal of European Social Policy 23(5): 469-86.

Engeli, Isabelle. 2012. "Policy Struggle on Reproduction Doctors, Women, and Christians." Political Research Quarterly 65(2): 330-45.

Fraser, Nancy. 1994. "After the Family Wage: Gender Equity and the Welfare State." Political Theory 22(4): 591-618.

Hancock, Ange-Marie. 2013. "Empirical Intersectionality: A Tale of Two Approaches." University of California Irvine Law Review 3: 259-96.

Krook, Mona Lena. 2010. "Women's Representation in Parliament: A Qualitative Comparative Analysis." Political Studies 58(5): 886-908.

McCall, L. 2005. “The Complexity of Intersectionality.” Signs 30(3): 1771-1800.

Ragin, Charles C. 1987. The Comparative Method: Moving Beyond Qualitative and Quantitative Strategies. Berkley: University of California Press.

Schneider, Carsten Q., and Claudius Wagemann. 2012. Set-Theoretic Methods for the Social Sciences: A Guide to Qualitative Comparative Analysis. Cambridge: Cambridge University Press.

Spierings, Niels. 2012. "The Inclusion of Quantitative Techniques and Diversity in the Mainstream of Feminist Research.” European Journal of Women's Studies 19(3): 331-47. 
Szelewa, Dorota, and Michal P. Polakowski. 2008. "Who Cares? Changing Patterns of Childcare in Central and Eastern Europe." Journal of European Social Policy 18(2): 115-31.

${ }^{1}$ Multilevel modelling is also intended to deal with context-specific effects (see Spierings in this Critical Perspective section).

2 To my knowledge, only Da Roit and Weicht's study (2013) using fsQCA to investigate the effect of various intersections of care, migration and employment on national patterns of migrant care work could be said to fall within the domain of intersectionality, although they do not explicitly assume this framework. 